\title{
A Study on the Cultivation of Tourism Talents in Colleges and Universities in the Age of Smart Tourism
}

\author{
Fengyun Wei
}

College of History and Culture, Changchun Normal University, Jilin, Changchun 130032)

\begin{abstract}
With recently increasing development in tourism, smart tourism, as a product of tourism and information technology development integration, has become the hotspot of tourism these years. Our higher institutions boost a galaxy of talents and technologies and take the key responsibility of cultivation of tourism talents in colleges and universities, which influences the development of smart tourism. On the one hand, it brings challenges for tourism growth in our higher institutions, on the other hand, it offers driving force on reform for cultivation of tourism talents in colleges and universities. In the era of smart tourism, colleges and universities should pay attention to the change of tourism industry, study the demand of tourism talents and adjust the traditional talents training methods in colleges and universities. Consequently, the tourism professionals in colleges and universities in line with the needs of smart tourism are fostered.
\end{abstract}

Keywords: Colleges and universities; Tourism major; Personnel training; Smart tourism

\section{智慧旅游时代高校旅游专业人才培养问题研究}

魏凤云

( 长春师范大学 历史文化学院, 吉林 长春 130032 )

摘要: 随着近年来旅游业的不断发展, 智慧旅游作为旅游业与信息技术发展融合的产物, 成为近年来旅游业备受瞩目 的热点。我国高校有着丰富的人才资源和科技资源, 承担着培养旅游专业人才的重大社会责任, 智慧旅游的发展离不开高 校智慧型旅游专业人才的培养, 这不仅为我国高校旅游专业的发展带来了挑战, 也为我国高校旅游专业培养智慧型旅游人 才提供了改革的动力。智慧旅游时代高校要时刻关注旅游业的变化, 研究旅游业对旅游专业人才的需求, 调整传统的高校 人才培养方式, 从而培养出符合智慧旅游时代需要的高校旅游专业人才。

关键词: 高校; 旅游专业; 人才培养; 智慧旅游

中图分类号: G441 文献标志码: A

引言

随着近年来旅游业与信息技术的发展和融合，游客数量与日俱增，游客对个性化服务的需求也不断 增加, 随时随地拥有大量的旅途信息成为了提升游客旅游质量的重要保证。随着旅游业这些新趋势、新 形态的不断变化, “智慧旅游” 理念在中国应运而生并且迅速发展, 目前智慧旅游已经成为旅游业的一 次重大并且深刻的变革, 影响着担负重大社会责任、不断为社会输送高品位、高质量人才的高校, 不仅给 高校旅游专业的发展带来了挑战, 也为高校旅游专业的智慧旅游人才培养提供了源源不断的动力。

2009 年, 在国家发布的《关于加快发展旅游业的意见》中指明要以信息技术为为主要手段, 提升旅 游业的服务质量; 我国将 “智慧旅游” 写入了《中国旅游业 “十二五” 规划纲要》中, 并对 “智慧旅游 城市” 试点工作进行了规划, 确立江苏镇江为 “国家智慧旅游服务中心”; 从 2001 年开始, 南京、扬 州、苏州、温州、北京等城市也相继宣布了建设 “智慧旅游城市” 的发展战略, 一些具备优秀旅游资源 的城市到目前为止已经取得了一定的成效 [1]；2014 年我国大力宣传名为 “美丽中国之旅一2014 年智慧 旅游年” 这一旅游主题; 2015 年 1 月, 我国旅游局在《关于促进智慧旅游发展的指导意见》, 提出要大力 
发展智慧旅游, 加强智慧旅游人才的培养, 这一指导意见的发布为智慧旅游人才的培养提供了重要保 障。

这些国家出台的政策以及区域智慧旅游的研究都推动了智慧旅游的发展以及信息技术在旅游业中的 应用, 这也必然要求我国的高等教育需要契合新的旅游发展趋势, 为旅游业的发展提供合格的、符合市 场需求的拥有智慧旅游专业素养的人才 $[2]$ 。

\section{1 我国大部分高校旅游专业人才培养方面的不足}

目前根据我国典型的高校旅游管理专业的课程设置，可以看出各高校的旅游管理专业都根据自身的 专业优势与特色对课程进行了调整和拓宽, 但是也在以下方面存在着需要改进的不足。

第一，课程的设置缺乏对高校旅游专业学生的科技素养的培养，不够贴合现代智慧旅游下人才的培 养目标。如, 在导游实训课上, 只注重培养学生的导游讲解能力, 导游服务能力以及协调组织能力等实 际操作能力而忽视了学生现代信息科学技术的掌握。随着云计算技术、物联网、互联网等高新技术不断 加入到旅游业中, 高校旅游专业的课程与电子商务等不断融合, 虽然各高校也在智慧旅游时代的背景下 做出了课程设置的调整, 但是高校旅游管理专业的学生还是普遍缺乏科技素养, 科技视野不够广阔, 尚 且无法满足飞速发展的旅游业对于旅游综合性人才的需求 [3]。

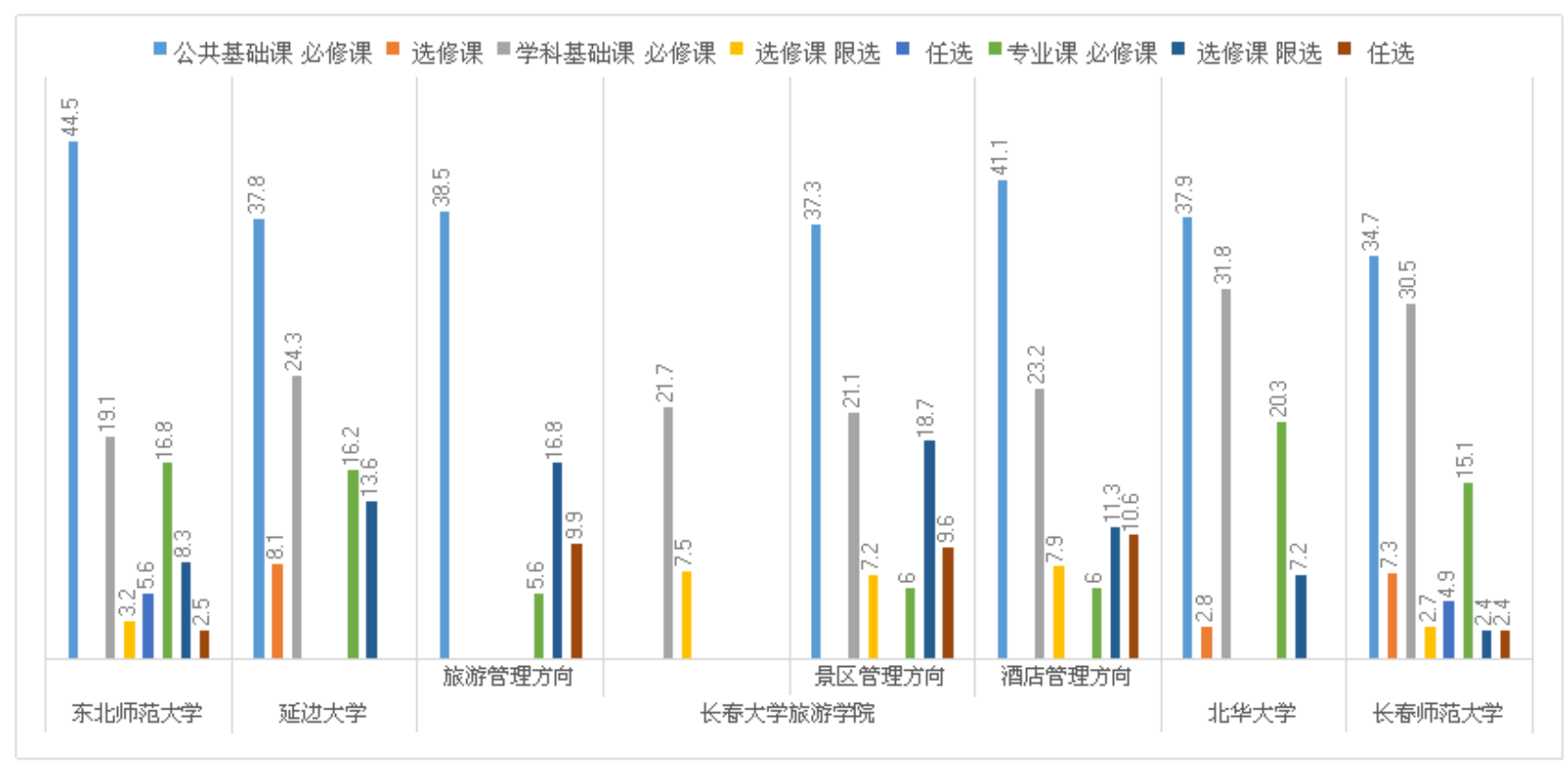

图 1 吉林省部分旅游高等院校课程设置性质与类型的比较

从各校开设的公共基础课、学科基础课及专业课的比例来看，课程设置在课程类型上重基础，轻专 业。各旅游高等院校公共基础课平均占总学时的 40\%以上, 学科基础课平均占总学时的 30\%左右, 而专业 主干课平均总学时不到总学时 $30 \%$ 的。从学时比来看, 公共课与专业课的平均比值为 $4.2: 5.8$, 这说明旅 游管理专业的本科学生在接受学校教育的过程中, 有四成以上的时间是用于大学语文、大学英语、大学 体育及思想政治类课程等公共必修课的学习, 而用于专业理论学习及实践的时间相对有限。在有限的这 段时间内, 又有一半的时间用于学科基础课的学习。从课程选择的自由度方面来看, 这五所院校中, 专 业选修课的课时比重分别为 $10.9 \% 、 13.5 \% 、 25.6 \% 、 7.2 \% 、 7.4 \%$, 在部分院校所设置的选修课中, 可供选 择的余地并不大。 
第二，学校提供的实践机会没有达到预期的效果，学生普遍缺乏实践。旅游管理专业对比于其他专 业而言, 学生的社会实践是至关重要的, 虽然我国目前各大旅游院校都进行了实践的教学, 但是各大院 校因为资金有限, 校内的实训基地大多设施、设备简唒, 导致学生的实践能力无法及时跟上旅游业的发 展水平, 毕业后就业时发现通常没有达到旅游企业需要的人才标准。各高校在校内进行实训时也在带领 学生不断地进行校外的实践活动, 但是往往出于对安全方面的考虑, 高校旅游管理专业对于学生的社会 实践都是十分谨慎, 致使一些实践活动仅仅局限于参观的层面, 对于学生实践能力的提高十分有限。

第三，人才培养缺乏特色，专业性不强。目前高校旅游管理相关培训课程开设的比较宽泛，例如旅 游经济学、管理学、市场营销学、旅游心理学、人力资源管理等一系列学科, 学生在学习这些学科时往 往只明白大体意思而没有对某一学科进行深入的研究, 这就使得学生在旅游领域缺乏自身特色, 在旅游 知识和能力的掌握上都不够专业，所以总是在工作岗位中难以实现自身价值。

第四, 高校旅游专业培养人才的目标不够明确, 培养出来的旅游专业的人才层次参差不齐, 导致本科 毕业生与旅游企业的用人标准相差悬殊。高等旅游教育人才培养目标诚然要与实践相结合, 培养行业紧 缺的高素质人才, 但事实上, 旅游教育产品的输出过程始终存在着滞后性, 如果旅游教育长时间地落后 于旅游业的发展，就会使得旅游人才在行业的适应度上 “慢半拍”。使高校旅游专业与旅游企业之间缺 乏长效的沟通机制以及渠道, 导致旅游业的人才缺口大, 就业率低、离职率高。

\section{2 智慧旅游时代对高校旅游专业人才的新要求}

智慧旅游的兴起，使旅游行业改变了传统的运营模式，旅游业更重视依托现代信息技术手段来发 展, 所以在旅游业深刻变革的今天, 旅游业对于高校旅游专业人才的培养也提出了新的要求。

\section{1 需要可以操作新媒体设施、设备的旅游专业人才}

智慧旅游是云计算技术、物联网、人工智能以及移动通信技术与旅游业相融合和发展的产物，目前 智慧旅游的转化, 在生活中的应用都需要依托新媒体的设施、设备, 简单地说就是智慧旅游的发展必须 要具有能携带信息技术的载体来完成, 比如说手机媒体、社交网络、微博、移动电视、数字电视等, 这些 新媒体迎合了消费者的心理, 把智能化的用户群体聚集到了一起, 提高了旅游服务质量, 增强了旅游企 业的竞争力, 创新了旅游者的体验方式, 也成为扩大旅游客源市场的重要途径, 推动了智慧旅游的发 展。所以作为高校旅游专业的人才掌握数字化新媒体的相关知识, 可以操作新媒体设施、设备是当前智 慧旅游时代的首要任务, 这也是当前高校培养旅游专业人才的重要任务 [4]。

\section{2 需要具有现代营销技能的旅游专业人才}

在旅游业竞争异常激烈的今天, 旅游者有越来越多的选择, 无论是从旅游信息的获取渠道、旅游产 品的价格、旅游产品质量等都是充分了解后才能进行最后的购买决定, 已经不单单是货比三家。现在用 手机或者电脑, 随意打开一个关于旅游出行的相关网站都会有大量的旅游信息扑面而来, 让人看过以后 眼花缭乱, 从价格到商品的质量, 不同等级层次的都有而且价格也是越来越划算, 那么在智慧旅游信息 高速发展的时代之下, 如何让你的旅游企业脱颖而出成为旅游者首选之地呢！这就需要旅游专业人才具 备现代的营销技能, 通过现代的智慧旅游平台传播旅游信息, 结合所学知识增加旅游产品的吸引力, 挖 掘游客的兴趣点, 充分利用现代的网络销售渠道, 时刻保持与旅游市场的紧密联系, 不断向游客传递旅 游商品的信息, 催生游客的购买欲并且牢牢抓住游客的购买机会, 有效的开展市场营销活动。 


\section{3 需要可以提供个性化服务的旅游专业人才}

随着智慧化旅游的兴盛，大多数游客开始选择散客游、自由行等出行方式，据不完全统计，北京旅 游的散客占到游客总数的 $91 \% ; 2015$ 年, 国内游客中, 独自出游比重为 $39.4 \% ; 2-3$ 人出游的占 $46.1 \%, 4$ 人及以上仅占 $1.45 \%$ 。随着旅游者出游方式的改变以及信息技术的广泛普及，未来旅游市场散客的份额将 会不断地扩大, 散客要求更加放松, 便利的旅游体验, 所以想要抓住需求各异的散客群体, 旅游专业的 人才必须具备可以提供专业化个性化服务的能力, 这便要求在智慧旅游时代下, 旅游高校对于旅游专业 人才的培养, 要根据旅游管理部门、旅游企业与旅游者提供的相关信息, 把旅游者的个性化需求进行分 析和归类，制定出能满足旅游者个性化需求的方案，从而提升旅游者的满意度 [5]。

\section{4 需要具有创新和智慧服务素质的人才}

智慧旅游时代，旅游企业和旅游从业人员通过运用现代科技手段来为旅游者提供服务，所以当旅游 从业人员为旅游者提供这种媒体上无形的服务的时候, 就需要旅游从业人员具备创新和智慧的服务理 念, 除了熟练的掌握基本的操作流程, 对于旅游者需要的个性化服务也要进行智慧的分析, 不断地为旅 游者提供新奇好玩的旅游策划方案。这里所提到的创新服务, 就是在智慧旅游时代这一大背景下, 旅游 从业人员要不断的接触新鲜事物, 变更以往的传统旅游观念, 在合理的情况之下, 用创新的理念去为游 客提供服务。而智慧服务就是能使旅游企业和旅游管理人员在信息时代趋利避害，运用智慧的分析，不 断总结旅游者的个性化需要从而制定计划, 使旅游企业和旅游从业人员与游客进行畅快的沟通 [6]。这就 要求高校在培训方式、教学内容等多方面进行教学创新, 建立新的人才培养模式, 提升旅游从业人员的 创新服务意识和智慧服务意识, 提高旅游专业毕业生的综合竞争力。

\section{5 需要掌握综合知识的旅游专业人才}

随着智慧旅游时代的到来, 旅游涉及的范围更加广泛, 旅游企业对于从业人员的要求也是越来越高, 智慧旅游时代背景下的旅游者也是较传统只是简单地观光的旅游者有很大的差异, 旅游不再是简单地观 光而是对于知识的深入探索以及文化方面的完全融入，这对于旅游从业人员来说也是一项很大的挑战， 不仅需要准确的掌握相关的导游讲解服务的知识、旅游地的文化知识, 还需要涉猎其他多方面的相关知 识, 这样才能贴合现代旅游者的思想观念。所以这也要求高校在培养旅游专业人才时, 设置的课程要及 时顺应智慧旅游在新时代背景下的发展新潮流, 打开旅游专业人才的眼界, 使旅游技术人才能充分的融 入到智慧旅游时代当中。

\section{3 智慧旅游时代对高校旅游专业人才培养的建议}

智慧旅游时代已经对高校旅游专业人才的素养提出了许多新的标准，高等院校在这些新要求之下如 何进行旅游专业的人才培养是值得去思考和实践的问题，高校旅游专业培养出高质量的旅游人才，有利 于提高我国旅游行业的整体发展水平, 也能加快推动智慧旅游的发展, 所以高校作为培养人才的主力军 一定要重视旅游专业人才的培养研究, 以下对智慧旅游时代高校如何进行旅游人才的培养研究提出了些 许建议:

\section{1 高校要明确人才培养的目标, 转变人才管理理念}

高校培养旅游专业人才的探索之路还很长, 目前我国大多数旅游高校对于人才的培养目标都锁定在 培养具有旅游管理专业知识, 具备商务、公关等业务的旅游专业人才。但是对于现在高速发展的旅游 
业, 这样的培养目标已经无法满足现代旅游企业的要求, 所以高校目前一定要明确人才培养的目标, 积 极主动地分析智慧旅游时代的需求, 着眼于整个行业未来的发展趋势, 可以使培养出来的人才把理论知 识与实践相融合, 提升整个旅游行业的就业率 $[7]$ 。

明确了高校人才培养的目标以后, 高校也需要对于现在传统的人才管理理念进行转变, 目前高校对 于旅游专业人才的管理主要是进行理论的教学以及一些简单地校内实践活动, 出于安全考虑, 一些外出 的实践活动也就是走马观花的参观一些酒店, 和传统的去旅游景点参观, 这样对于人才的管理理念已经满 足不了智慧旅游背景下旅游业的发展, 高校在这种大环境下, 必须树立起培养智慧型旅游人才的理念, 不断地分析目前的旅游市场, 并且转变培养旅游专业人才的方式, 为整个旅游行业提供源源不断的高质 量人才。

\section{2 高校要拓宽旅游专业的课程体系, 提升学生的信息素质}

目前, 高校旅游专业的课程体系基本划分为公共必修课程、通识选修课程、学科专业必修课程以及 学科专业选修课程等四个模块, 作为传统的教学内容对于旅游业出现的新业态关注不够, 可以适当拓宽 课程体系, 增加新的教学内容 $[8]$ 。

在智慧旅游的趋势下，高校应该把旅游专业的课程与电子商务以及信息技术等课程联系到一起，拓 宽旅游专业的课程体系, 提升高校旅游专业学生的信息素质, 高校可以结合旅游类课程的特点, 增加有 关于信息化的课程设置, 比如旅游电子商务、酒店电子商务等课程, 在课程的教授方式上, 充分结合现 代智慧旅游时代旅游业发展的情况, 让学生参与到课程的设置与讨论当中, 高校可以安排学生对当地的 智慧旅游平台进行调研, 提出问题进行分析找到解决问题的措施, 在这种实践当中让学生零距离的与现 代智慧旅游相接触, 同时也也保证了高校课程设置的完整性, 加强了高校信息化课程的深度, 为旅游行 业输送高品质的智慧型人才做出了充分的准备。

\section{3 高校要大力打造智慧型的教师队伍}

教师作为知识的传播者, 担负着培养人才的重大责任, 在智慧旅游时代高校的教师更要牢牢地抓住 时代的脉搏, 走在时代的前沿。

首先, 高校要培养教师掌握智慧旅游相关知识以及信息技术手段, 多开展一些校内的关于信息技术 的培训, 学校组织教师到一些当地知名的旅游企业进行兼职培训以及学习。其次, 教师要不断学习吸取 知识, 本身智慧旅游时代就是一个信息量非常大的时代, 作为旅游专业的教师要不断地把智慧旅游的相 关理论与信息进行智慧化的编辑和整理, 然后通过课堂的智慧旅游案例的导入让学生在积极主动地状态 下学习智慧旅游的相关知识, 让教师与学生共同感受智慧旅游时代的脉搏。最后, 一些旅游相关的管理 部门, 也要不断的鼓励旅游专业的教师, 制定相应的制度, 保证教师能与智慧旅游充分接轨, 把智慧旅 游充分融入到自身的教学当中, 所以必须提高高校教师的专业素养 [9]。

\section{4 高校要与智慧旅游企业合作办学培养旅游人才}

针对于现在智慧旅游时代旅游专业毕业生工作不对口, 流失率大的特点, 高校可以与智慧型的旅游 企业进行合作比如智慧酒店、智慧景区等行业, 这样不仅可以缓解高校资金贯乏无法为学生提供完善的 实践操作的设施, 还可以降低学校教育的成本, 重要的是企业可以针对现在智慧旅游的需要针对性的培 养旅游专业的人才, 实现旅游企业与高校的无缝对接, 比如说上海旅游高等专科学校就把旅游专业的同 
学实习安排在了像同程、途牛这样的智慧型旅游企业, 山东的旅院也从 2010 年与同程网进行合作。高校 与拥有信息技术的旅游企业进行合作不仅能让高校旅游专业的学生通过实际操作不断提升自身的关于智 慧旅游的素养，同时也对智慧旅游的快速发展起到了推动作用 $[10]$ 。

\section{5 高校旅游专业人才自身要提高智慧旅游专业素养}

身为高校旅游专业的人才，要时刻关注旅游行业的整体变化，结合旅游本科院校根据智慧旅游制定 的人才培养理念、人才培养目标、人才培养内容及人才培养方式找到自身适合的学习方式以及方法, 通 过不断学习和掌握现代的信息技术手段, 提升自身的智慧旅游专业素养例如现代旅游软件的使用以及各 大景区智慧旅游相关的建设都应该掌握, 这样在以后从事旅游行业时才能脱颖而出, 才能在旅游企业工 作时能体现高校旅游专业人才的智慧旅游素养。

\section{4 结语}

智慧旅游作为目前旅游业的重要组成部分影响着我国旅游业的发展，也给肩负着培养旅游专业人才 的高校提出了新的人才培养要求, 本文通过对智慧旅游时代需要可以操作新媒体设施、设备, 具有现代 营销技能, 可以提供个性化服务, 具有智慧和创新服务素质, 掌握综合知识的旅游专业人才的分析, 为智 慧旅游时代高校应如何培养旅游专业人才提出了建议, 建议高校要明确自身人才培养的目标, 转变人才 管理的理念, 通过拓宽课程体系, 提升学生的信息素养, 打造智慧型的教师队伍, 与企业联合办学培养 旅游专业人才。以期改善旅游人才培养的现状, 为旅游企业增加更多的人才支撑, 促使旅游业更好更快 的发展。

\section{5 致谢}

感谢以下基金项目的资助：吉林省教育厅 2015 年人文社会科学基金项目《吉林省智慧旅游建设的总 体架构研究》资助（编号：2015280); 长春师范大学人文社会科学基金项目《吉林省智慧旅游建设模式 研究》资助（编号：2014003）。

\section{参考文献:}

[1] 张凌云, 黎㟽, 刘敏. 智慧旅游的基本概念与理论体系[J]. 旅游学刊, 2012(5): 66-73.

[2] 杨华. “智慧旅游”的发展与旅游专业课堂教学方法改革探讨[J]. 旅游纵览(下半月), 2014(05): 84-86.

[3] W.K. Tan and T.H. Chen. The usage of online tourist information sources in tourist information search: An exploratory study, Service Industries Journal, 2012(3):451-476.

[4] Ulrike Gretzel. Review artical intelligent system in tourism: A social science perspective[M]. Annals of Tourism Research, 2011,38(3):757-779.

[5] Takashi Hasuike and Takumi Ichimura.Web intelligence for tourism using railway data by a simplified fuzzy reasoning method, Journal of Intelligent and Fuzzy Systems ,2013(24):251-259.

[6] 张丹宇. 高校旅游管理专业应用型创新人才培养模式[J]. 学术探索, 2015: 73-77.

[7] 王格. 智慧旅游背景下高职旅游专业人才培养模式探讨[J]. 高等职业教育(天津职业大学学报), 2014(05): 42-45.

[8] Unai Bastidaa. Performance evaluation of tourism websites' information quality of four global destination brands: Beijing, Hong Kong, Shanghai, and Taipei [J].Journal of Business Research, 2013, 67(2):167 170.

[9] 郑向敏, 范向丽. 论旅游专业“四高”的人才培养理念与运作模式[J]. 人文地理, 2010(06): 146-149.

[10] Peter McLaren. Life in Schools: An Introduction to Critical Pedagogy in the Foundations of Education (Sixth Edition)[M]. Paradigm Publishers. 2014. 


\section{References:}

[1] Zhang Lingyun, Li Nao, Liu Min. Basic Concepts and Theoretical System of Smart Tourism [J].Tourism Tribune, 2012(5):66-73.

[2] Yang Hua. Discussion on Development of "Smart Tourism" Classroom Teaching Method Reform of Tourism Major [J].Tourism Overview (Second Half), 2014(05):84-86.

[3] W.K. Tan and T.H. Chen. The usage of online tourist information sources in tourist information search: An exploratory study, Service Industries Journal, 2012(3):451-476.

[4] Ulrike Gretzel. Review artical intelligent system in tourism: A social science perspective [M]. Annals of Tourism Research, 2011, 38(3):757-779.

[5] Takashi Hasuike and Takumi Ichimura. Web intelligence for tourism using railway data by a simplified fuzzy reasoning method, Journal of Intelligent and Fuzzy Systems, 2013(24):251259.

[6] Zhang Danyu. Talents Training Mode of Applied Innovative in Tourism Management Major of Colleges and Universities [J].Academic Exploration, 2015: 73-77.

[7] Wang Ge. Research on Talents Training Mode of Tourism Major in Vocational High School under Background of Smart Tourism [J].Higher Vocation Education (Journal of Tianjin Vocational Institute),2014(05):42-45.

[8] Unai Bastidaa. Performance evaluation of tourism websites' information quality of four global destination brands: Beijing, Hong Kong, Shanghai, and Taipei [J].Journal of Business Research, 2013, 67(2):167 170.

[9] Zheng Xiangmin, Fan Xiangli. On Personnel Training Concept Operation Mode of "Four High" Travel Travel [J].Human Geography, 2010(06):146-149.

[10] Peter McLaren. Life in Schools: An Introduction to Critical Pedagogy in the Foundations of Education (Sixth Edition) [M]. Paradigm Publishers. 2014. 